\title{
Distinct cognitive and discriminative stimulus effects of ketamine enantiomers in rats
}

\author{
Piotr Popik $^{1} \dagger$, Shaun Yon-Seng Khoo ${ }^{2}$, Agata Kuziak', Joanna Golebiowska', \\ Agnieszka Potasiewicz ${ }^{1}$, Adam Hogendorf ${ }^{3}$, Oskar Popik ${ }^{4}$, Mikolaj Matloka ${ }^{5}$, \\ Rafal Moszczynski' ${ }^{5}$, Agnieszka Nikiforuk', and Jeffrey M. Witkin ${ }^{6,7,8}$
}

${ }^{1}$ Behavioral Neuroscience and Drug Development, Maj Institute of Pharmacology, Polish Academy of Sciences, Smętna 12, 31-343 Kraków, Poland

${ }^{2}$ Department of Pharmacology and Physiology, Faculty of Medicine, Universite de Montréal, Montreal, QC, Canada

${ }^{3}$ Department of Medicinal Chemistry, Maj Institute of Pharmacology, Polish Academy of Sciences, Smętna 12, 31-343 Kraków, Poland

${ }^{4}$ Institute of Organic Chemistry, Polish Academy of Sciences, Kasprzaka 44/52, 01-224 Warszawa, Poland

${ }^{5}$ Celon Pharma, Warszawa, Poland

${ }^{6}$ Department of Neuroscience, Ascension St. Vincent Hospital, Indianapolis, IN, USA

${ }^{7}$ Department of Chemistry and Biochemistry University of Wisconsin-Milwaukee, Milwaukee, WI, USA

${ }^{8}$ Department of Trauma Research, Ascension St. Vincent Hospital, Indianapolis, IN, USA

This is the accepted manuscript version of the article. The final typeset version may be accessed via https://doi.org/10.1016/j.pbb.2020.173011. In accordance with Elsevier's article sharing policy, this accepted manuscript version may be used under a Creative Commons Attribution Non-Commercial No-Derivatives 4.0 International License.

Although $(S)$-ketamine was approved for use in treatment-resistant depression in 2019, new preclinical findings suggest that $(R)$-ketamine might produce better efficacy and tolerability relative to $(S)$-ketamine. Here we evaluated the effects of $(R)$-, $(S)$-, and $(R, S)$ ketamine on executive functions as measured in the attentional set shifting task (ASST) and on their discriminative stimulus effects in rats. Earlier data demonstrated that cognitive flexibility is compromised by $(R, S)$-ketamine, but the effects of enantiomers in rats are unknown. Separate cohorts of rats were tested in ASST and trained to discriminate either $(R, S)$-ketamine, $(S)$-ketamine, or $(R)$-ketamine (all at $10 \mathrm{mg} / \mathrm{kg}$ ) from saline; in order to maintain the discrimination, a higher $(R)$-ketamine dose $(17.5 \mathrm{mg} / \mathrm{kg})$ was subsequently instituted. In ASST, all three forms increased the trials to criterion measure at reversal learning and extra-dimensional set-shifting phases. However, in contrast to $(R)$ - and $(S)$-ketamine, $(R, S)$-ketamine prolonged the mean time to complete a single trial during early stages, suggesting increased reaction time, and/or unspecific side-effects related to motor or motivational impairments. In the drug discriminations, all rats acquired their respective discriminations between drug and saline. In $(R, S)$-ketamine-trained rats, $(R)$-ketamine and $(S)$-ketamine only partially substituted for the training dose of $(R, S)$-ketamine. Further, $(R)$-ketamine did not fully substitute in rats trained to $(S)$-ketamine. The data suggest more serious cognitive deficits produced by $(R, S)$-ketamine than its enantiomers. Furthermore, $(R, S)$-ketamine and its isomers share overlapping but not isomorphic discriminative stimulus effects predicting distinct subjective responses to $(R)$ - vs. $(S)$-ketamine in humans.

† Email address for correspondence: nfpopik@cyf-kr.edu.pl 


\section{Introduction}

Ketamine, a structural analog of phencyclidine (PCP), was first synthesized in 1962 under the name CI-581 by Calvin Stevens (see historical overview by Mion (2017)). Just a few years later, ketamine was reported to be a general anesthetic in animals and studied in humans by Domino et al. (1965) who termed ketamine a dissociative anesthetic. Some 40 years after its synthesis, data on effects of ketamine in patients with major depressive disorder began a revolution in the field of neuropsychiatry. Zarate et al. (2006) from the U.S. National Institutes of Health reported that a 40 min infusion with ketamine at a sub-anesthetic dose was able to produce immediate response in patients suffering from treatment-resistant depression. These effects were prefaced by the work of Berman et al. (2000) in depressed patients and by the preclinical predictions of efficacy of ketamine in depression by Trullas and Skolnick (1990) 10 years earlier. Twenty-three years earlier, the NMDA receptor antagonist actions of ketamine were first disclosed (Anis et al. 1983). The rapid onset of antidepressant effect, the ability to impact treatment-refractory patients, and the relatively large effect size of ketamine's antidepressant effects immediately caught the attention of the scientific research and patient communities.

In 2019, the $(S)$-isomer of ketamine (esketamine) was approved for use in treatmentresistant depression in the United States (Spravato) and in Europe (Cristea \& Naudet 2019). Ketamine also has potential as a therapeutic agent for pain (Nielsen et al. 2019; Persson et al. 1998), substance abuse disorder (Dakwar et al. 2020; Jones et al. 2018; Witkin et al. 2020), and other psychiatric disorders such as obsessive- compulsive disorder and anxiety disorders (Banov et al. 2019) as well as post-traumatic stress disorder (Liriano et al. 2019). The promise of ketamine as a medicine is tempered by safety, tolerability, and side-effect issues. Ketamine produces psychotomimetic and dissociative effects and can produce anxiety and dysphoria (Nugent et al. 2019). Ketamine is also a drug with high abuse potential (Ji Kwon \& Han 2019). Of particular importance are ketamine-induced cognitive disturbances in humans that are expressed as impaired performance on tests of vigilance, verbal fluency, and the Wisconsin Card Sorting Test, indicating frontal cortical dysfunction (Krystal et al. 1994).

These pharmacological effects of racemic ketamine have led researchers to look for a 'milder and gentler ketamine' with comparable efficacy. This search has gone in a host of directions and led to several potential lead molecules and mechanisms (c.f. Hashimoto 2019; Witkin et al. 2019, 2020). Although S(+)-ketamine was the isomeric form approved as a medicine for depression, accumulating data have recently suggested that $\mathrm{R}(-)$ ketamine might be superior for patients. In preclinical studies, $(R)$-ketamine is more potent and longerlasting than $(S)$-ketamine in its antidepressant-like effects in rodents (Chang et al. 2019; Fukumoto et al. 2017; Zhang et al. 2014). Rodent data also point to the possibility that $(R)$-ketamine might be an improvement over $(S)$-ketamine in tolerability and safety. In these studies $(R)$-ketamine produced less psychotomimetic effects and abuse liability than $(S)$-ketamine (Chang et al. 2019; Yang et al. 2015, see also Zanos et al. 2018).

Neuroimaging studies in nonhuman primates have suggested a basis for these behavioral observations. $(S)$-ketamine but not $(R)$-ketamine increased dopamine release in the striatum, a neurochemical phenomenon associated with psychotomimetic effects (Hashimoto et al. 2017). (S)- but not (R)-ketamine produced anhedonia-like effects in rats that electrically self-stimulated the medial forebrain bundle (Witkin et al. 2020). Data from the few studies evaluating $(R)$-ketamine in humans have also indicated milder effects of the $(R)$-isomer. Persson et al. (2002) reported that $(R)$-ketamine induced less 
subjective reports than $(S)$-ketamine (drunk, dream-like, floating, distorted experience). And, one study showed qualitative differences in reactions to ketamine isomers in humans. In a study by Vollenweider et al. (1997), (S)-ketamine produced psychotic-like effects whereas comparable doses of $(R)$-ketamine produced calmness. A more recent study confirmed the prediction that $(R)$-ketamine would be antidepressant at doses engendering a relatively benign side-effect profile. A small $(n=7)$ open label study showed efficacy of $(R)$-ketamine infusion in treatment-resistant depressed patients without inducing dissociative-like effects (Leal et al. 2020). Interestingly, all patients reported the sensations of serenity and inner peace with (R)-ketamine (Leal et al. 2020).

Given the rodent and human data that align to show that $(R)$-ketamine might produce quantitatively and qualitatively distinct pharmacological effects, we asked the question as to whether $(R, S)$-, $(R)$ - and $(S)$ - ketamine might produce distinct cognitive impairments and discriminative stimulus effects in rats. To measure cognitive effects of ketamines we used the attentional set shifting task (ASST), based on the human test analog, the Wisconsin Card Sorting Test, that assesses cognitive flexibility, that is, the ability to modify behavior in response to changes in the relevance of discriminative stimuli. In this paradigm, rats must select a bowl containing a food reward based on the ability to discriminate the odors or the media covering the food (Birrell \& Brown 2000). The ASST requires rats to initially learn a rule and form an attentional "set" within the same stimulus dimensions. At the extradimensional (ED) shift stage, animals must switch their attention to a previously irrelevant stimulus dimension (e.g., discriminate between the odors and not between the media). The animal's performance at the ED stage is considered an index of cognitive flexibility. Ketamine-induced cognitive inflexibility observed in humans (Krystal et al. 1994) and in the ASST in rats (Nikiforuk et al. 2010; Potasiewicz et al. 2019), suggests high translational value of this test. However, the differences in cognitive effects of racemic ketamine and its enantiomers have not been examined in rodents. In the present study we directly compared the cognitive impairment produced by $(R, S)$-, $(R)$ - and $(S)$-ketamine using the ASST.

In drug discrimination studies, rats are trained to report the presence of a drug vs. its absence. The ability of another drug to substitute for the training drug has been used as a valid predictor of the subjective effects of drugs in humans (Holtzman 1985; Schuster \& Johanson 1988). For example, Balster \& Willets (1988) showed that uncompetitive NMDA receptor antagonists produce a common discriminative stimulus effect in rats as they produce similar subjective reports in humans. Drug discrimination studies are one of the tests often required by the U.S. Food and Drug Administration (FDA) and the Drug Enforcement Agency (DEA) in assessing abuse liability and this assay is validated for ketamine-like drugs (Klein et al. 1999). Moreover, these methods are adaptable to humans (Bolin et al. 2016; Schuster \& Johanson 1988). Given the utility of drug discrimination data, these studies have been used to identify compounds with reduced liabilities for engendering specific subjective effects in humans. For example, the idea that glycine-site antagonists of NMDA receptors might not produce PCP-like subjective responses was studied in rats trained to discriminate PCP from drug vehicle (Witkin et al. 1997). Drug discrimination data constituted the basis for the bet that GLYX-13 would not produce subjective effects like that of PCP (Burgdorf et al. 2013), a prediction born out in antidepressant trials in patients (Preskorn et al. 2015). Here, we trained separate groups of rats to discriminate $(R, S)$-ketamine from vehicle, $(S)$-ketamine from vehicle, or $(R)$-ketamine from vehicle. After training, when the rats had achieved $\geqslant 85 \%$ accuracy in selecting the drug- from the vehicle-associated response alternative, we substituted the other isomeric drug forms. Based upon the differential effects of these 
drug forms summarized above, we predicted that $(R)$ - and $(S)$ - ketamine would display distinct discriminative stimulus effects.

\section{Methods}

\subsection{Animals and ethics}

Thirty (ASST) and 23 (drug discrimination) male Sprague-Dawley rats (Charles River, Germany) weighing $250 \mathrm{~g}$ upon arrival were group housed (5 per cage) in standard laboratory cages, under standard colony controlled conditions: room temperature 21 $\pm 2{ }^{\circ} \mathrm{C}$, humidity (40-50\%), 12-hr light/dark cycle (lights on: $06: 00$ ) with ad libitum access to water and with a mild food restriction for at least one week prior to training. Rats were allowed to acclimatize for at least 7 days before the start of the experimental procedure; during this time the animals were frequently handled. At least $1 \mathrm{~h}$ before the start of experimental procedures, rats were transferred to the experimental room for acclimation.

In both studies, $17 \mathrm{~g}$ per day per animal of standard laboratory chow was provided $1 \mathrm{~h}$ after the training or testing sessions, i.e., at 13:00. The animals were group-fed in their home cages. On most of the weekend days no sessions were conducted, and the animals were given the same amount of $17 \mathrm{~g} / \mathrm{rat}$ of food starting at 13:00. All animals were maintained, and experiments were conducted in accordance with the European Guidelines for animal welfare (2010/63/EU) and all experimental procedures were approved by the II Local Ethics Committee for Animal Experiments at the Maj Institute of Pharmacology, Polish Academy of Science, Krakow, Poland. None of the rats had previously received drugs or behavioral training.

\subsection{Drugs}

$(R, S)$-ketamine $(115.34 \mathrm{mg} / \mathrm{ml}$ of an aqueous solution, Vetoquinol Biowet, Gorzow Wielkopolski, Poland), (R)-ketamine HCl (Seqens, Germany), and (S)-ketamine HCl (Celon Pharma, Warsaw, Poland) were dissolved in sterile water on the day of training or testing. Sterile $0.9 \%$ physiological saline served as the control solution.

\subsubsection{Chemistry}

To ensure that the enantiomeric forms of ketamine used in the present study were the forms as stated, we employed analytical methods. Optical rotation measurements of ketamine hydrochlorides were carried out in water using a Jasco P-2000 polarimeter (Tokyo, Japan). Next, the aqueous ketamine $\mathrm{HCl}$ solution was basified with $10 \% \mathrm{NaOH}$ solution and the free amine was extracted with diethyl ether. The organic phase was dried over anhydrous $\mathrm{Na}_{2} \mathrm{SO}_{4}$, filtered, concentrated in vacuo to dryness and submitted for enantiomeric excess determination with HPLC. HPLC analyses were performed on a Jasco HPLC system (Tokyo, Japan) equipped with a Daicel column with a chiral stationary phase (CHIRALCEL OD-H) and a UV detector (detection at $254 \mathrm{~nm}$ ).

\subsubsection{ASST study}

The cognitive effects of $(R, S)$-ketamine $(10 \mathrm{mg} / \mathrm{kg}$, SC, given $1 \mathrm{~h}$ before the test) were reported by our laboratory (Nikiforuk et al. 2010; Potasiewicz et al. 2019). Therefore, in the present study we used the racemate and ketamine enantiomers at the same doses of $10 \mathrm{mg} / \mathrm{kg}$. 


\subsubsection{Drug discrimination study}

Injections were given intraperitoneally (IP), 15 min before training and testing in a volume of $1 \mathrm{ml} / \mathrm{kg}$. The choice of doses and of the time between drug administration and the experimental session was based on earlier work (Chiamulera et al. 2016; Kos et al. 2006). Initially, all ketamines were administered at the dose of $10 \mathrm{mg} / \mathrm{kg}$. However, we observed similar effects as in the De Vry \& Jentzsch (2003) study who started the drug discrimination experiment with $5 \mathrm{mg} / \mathrm{kg}$ of ketamine, and due to the difficulty in reaching stable discrimination performance within the first 40 sessions, raised the training dose to $7.5 \mathrm{mg} / \mathrm{kg}$. Our $10 \mathrm{mg} / \mathrm{kg}(R)$-ketamine trained rats also had difficulty in reaching stable discrimination performance within the first 50 sessions, and therefore we increased the training dose from the starting dose of $10 \mathrm{mg} / \mathrm{kg}$ to $17.5 \mathrm{mg} / \mathrm{kg}$ of $(R)$ ketamine. $(R)$-ketamine animals received this dose to the end of the study. While we are aware that this creates difficulty with comparisons across groups due to the difference in training dose $(10 \mathrm{mg} / \mathrm{kg}$ of $(R, S)$ - and $(S)$-ketamine vs. $17.5 \mathrm{mg} / \mathrm{kg}$ of $(R)$-ketamine), the dose escalation of $1 / 4 \log$ unit was necessary for behavioral control. Thus, the final doses used to maintain the drug discriminations were $10 \mathrm{mg} / \mathrm{kg}$ for $(R, S)$-ketamine and for $(S)$-ketamine and $17.5 \mathrm{mg} / \mathrm{kg}$ for $(R)$-ketamine.

\subsection{ASST}

\subsubsection{Apparatus}

Testing was conducted in a dimly illuminated (20 Lux) Plexiglas apparatus (length $\times$ width $\times$ height: $38 \times 38 \times 17 \mathrm{~cm}$ ) with the grid floor and wall dividing half of the length of the cage into two sections. During testing, one ceramic digging pot (internal diameter of $10.5 \mathrm{~cm}$ and a depth of $4 \mathrm{~cm}$ ) was placed in each section. Each pot was defined by a pair of stimulus cues with two stimulus dimensions (odor and digging medium). To mark each pot with a distinct odor, $5 \mu$ l of a flavoring essence (Dr. Oetker ${ }^{\circledast}$, Poland or The Body Shop, UK) was applied to a piece of blotting paper fixed to the external rim of the pot immediately prior to use. A different pot was used for each combination of digging medium and odor; only one odor was ever applied to a given pot. The bait (onehalf of a Honey Nut Cheerio, Nestle ${ }^{\circledR}$ ) was placed at the bottom of the "positive" pot and buried in the digging medium. A small amount of powdered Cheerio was added to the digging media to prevent the rat from trying to detect the buried reward by its smell.

\subsubsection{Procedure}

As described previously (e.g. Potasiewicz et al. 2019), the procedure was conducted over a period of three consecutive days for each rat.

Day 1, habituation: rats were habituated to the testing area and trained to dig in the pots filled with sawdust to retrieve the food reward. The rats were transported from the housing facility to the testing room where they were presented with one unscented pot (filled with several pieces of Cheerios) in their home cages. After the rats had eaten the Cheerio from the home cage pot, they were placed in the apparatus and given three trials to retrieve the reward from both of the sawdust-filled baited pots. With each exposure, the bait was covered with an increasing amount of sawdust. Animals that did not dig for a food reward over 3 consecutive daily sessions were excluded from the experiment.

Day 2, training: rats were trained on a series of simple discriminations (SDs) to a criterion of six consecutive correct trials. For these trials, the rats had to learn to associate the food reward with an odor cue (e.g., arrack vs. orange, both pots filled with sawdust) and/or a digging medium (e.g., plastic balls vs. pebbles, no odor). All rats were trained using the same pairs of stimuli. The positive and negative cues for each rat were 
presented pseudo-randomly and equally. These training stimuli were not used again in later testing trials.

Day 3, testing: rats performed a series of discriminations in a single test session. The first four trials at the beginning of each discrimination phase were discovery trials, during which the animals were allowed to dig in both bowls. The first trial of the discovery period was not included in the six criterion trials. In the subsequent trials, each incorrect choice was recorded as an error. Digging was defined as any distinct displacement of the digging media with either the paw or the nose; the rat could investigate a digging pot by sniffing or touching without displacing material. Testing was continued at each phase until the rat reached the criterion of six consecutive correct trials, after which testing proceeded to the next phase.

In the simple discrimination involving only one stimulus dimension, the pots differed along one of two dimensions (e.g., digging medium). For the compound discrimination (CD), the second (irrelevant) dimension (i.e., odor) was introduced, but the correct and incorrect exemplars of the relevant dimension remained constant. For the reversal of this discrimination ( $\operatorname{Rev} 1$ ), the exemplars and the relevant dimension were unchanged, but the previously correct exemplar was now incorrect, and vice versa. The intra-dimensional (ID) shift was then presented, comprising new exemplars of both the relevant and irrelevant dimensions, with the relevant dimension remaining the same as previously described. The ID discrimination was then reversed ( $\operatorname{Rev} 2$ ) so that the formerly positive exemplar became the negative one. For the extra-dimensional (ED) shift, a new pair of exemplars was again introduced; however, this time, the relevant dimension was also changed. Finally, the last phase was the reversal (Rev 3) of the ED discrimination.

The following pairs of exemplars were used: Pair 1: odor: spicy vs. vanilla, medium: cotton wool vs. crumpled tissue; Pair 2: odor: lemon vs. almond, medium: shredded pipette tips vs. wooden sticks; and Pair 3: odor: rum vs. cream, medium: shredded papers vs. silk. The exemplars were always presented in pairs, and they varied so that only one animal within each treatment group received the same combination. The assignment of each exemplar in a pair as being positive or negative at a given phase and the left-right positioning of the pots in the test apparatus on each trial were randomized.

Each rat was tested no more than twice, with at least a 7-day washout period between each of the two tests. No animal received the same treatment twice. As our previous study demonstrated the stability and reproducibility of the performance of rats during repeated testing on the ASST (Potasiewicz et al. 2019), the repeated testing paradigm was used in the current experiments to reduce the number of animals used.

\subsection{Drug discrimination}

\subsubsection{Apparatus}

Six operant conditioning chambers (Med Associates, St Albans, VT, USA) measuring $56 \mathrm{~cm} \times 56 \mathrm{~cm} \times 40.5 \mathrm{~cm}$ were housed in soundattenuated and ventilated cubicles. Each chamber was equipped with two nose-poke oparanda and a food magazine equipped with photocell beam detectors and a light was located on the opposite wall. A house light ( $5 \mathrm{~W}$ white bulb) was located $17 \mathrm{~cm}$ above the top edge of the food magazine. Food pellets (45 mg, Bioserve Dustless Precision Pellets, Frenchtown, NJ, USA) were delivered via a dispenser connected to the food magazine. Online control of the apparatus and data collection was performed using MED-PC software (Med Associates). An exhaust fan provided continuous masking noise. Following every session, the chambers were 
cleaned to avoid olfactory cues which may be deposited by animals and serve as discrimination cues for other rats tested in the same chamber (Extance \& Goudie 1981).

\subsubsection{General procedure}

2.4.2.1. Initial training. Animals were trained for $20 \mathrm{~min}$ to poke into either hole on a fixed-ratio 1 (FR1) reinforcement schedule in which each response produced food. After the rats had acquired this behavior, they were trained for 20 min to poke on an FR1 schedule in one of the holes while poking into the other hole had no scheduled consequences. When responding stabilized, training was shifted to reinforcing responses in the hole formerly non-reinforced. In this way, the rats were given discriminate training on both nose holes.

\subsubsection{Discrimination training}

The drug discrimination procedure used was based on the classical work of Glennon et al. (1983) and Gresch et al. (2007). Briefly, the rats were trained every day at the same time ( 09:00) Monday-Friday to discriminate a given form of ketamine from sterile saline under a double alternating sequence, with at least two ketamine and two vehicle sessions per week (e.g., K-K-V-V-K; Popik et al. 2019). Administration of ketamine or saline 15 min prior to a variable interval $15 \mathrm{~s}$ (VI-15) schedule of reinforcement served as the discriminative cue for the correct (reinforced) nose-poke.

Training sessions, during which correct responding was reinforced for the entire 20-min session, were interspaced with extinction sessions. Extinction sessions were carried out twice per week at most, were always preceded with the training ketamine or vehicle session and were used to assess the degree of stimulus control exerted by ketamine or saline (Glennon et al. 1983). The extinction session consisted of a 2.5-min nonreinforced test period, followed by "normal” 17.5-min training during which correct responses were reinforced (Stadler et al. 1999). To facilitate discrimination performance, a 5-sec time-out after incorrect responding was introduced during which reinforcement was withheld for responses on the correct hole.

2.4.3.1. Testing sessions. Once a stable level of performance was attained $(\geqslant 85 \%$ of responses on the ketamine-appropriate hole after administration of ketamine and $\leqslant 15 \%$ of the total responses on the same hole after administration of saline), generalization studies were conducted. These testing sessions were carried out once a week, usually on Fridays or Saturdays and were always preceded by the given ketamine or saline training session. Rats were given generalization testing only if they met the stable response criteria the day before. Doses were fully randomized for each rat. For every individual generalization study, statistical comparison included specific data of the given ketamine or saline training session preceding the test. Statistical comparisons of responding on generalization tests were made by direct comparison to the preceding control session.

There were two differences between the training and the testing session. While in the training session (that lasted for $20 \mathrm{~min}$ ) the correct responses were always reinforced, in the testing session (2.5 $\mathrm{min})$, responses into either hole were never reinforced. Testing in the extinction conditions was done to prevent new discrimination learning (Colpaert 1987). Immediately after the session was terminated, the rat was removed from the testing chamber and placed in his home cage.

\subsection{Study design}

The cohort of 23 rats was randomly divided into three groups of animals that were trained, following $(R, S)$-ketamine $(\mathrm{N}=9),(R)$-ketamine $(\mathrm{N}=7)$ and $(S)$-ketamine $(\mathrm{N}=$ 
7) administration, to poke into one hole and, in another experimental session following vehicle administration, to poke into the other hole. For approximately $50 \%$ of rats the left hole was designated as the ketamine hole, and for the remaining animals, the right hole was so defined. For all animals, the side assignments remained unchanged throughout the study.

\subsection{Statistics}

\subsubsection{ASST}

The number of trials required to achieve the criterion of six consecutive correct responses (i.e., trials to criterion, TTC) was recorded for each rat and for each discrimination phase of the ASST. In addition, we analyzed the mean time taken to complete every trial in a given SD, CD, Reversal 1, ID, Reversal 2, ED and Reversal 3 phases. Data were analyzed using a mixed design 2-way ANOVA with treatment (Veh, $(R, S)$-, $(R)$-, $(S)$-) as a between-subject factor and discrimination phase (SD, CD, Rev. 1, etc.) as a repeated measure. As a post-hoc test, we used Newman-Keul's test. Statistica 12 (Stat Soft, USA) was used throughout.

\subsubsection{Drug discrimination}

Due to attrition of animals not meeting response criteria for drug testing, the number of data points for some experiments was low. In order for data to be included in statistical analyses, $N$ values of $5-10$ were required, with the exception of one data point with $\mathrm{N}=4$ (the latter was embedded within a dose-response curve with total $\mathrm{N}$ of 27 ). To estimate the dose of drug required to produce 50\% drug responding (ED50) with 95\% confidence limits, response accuracy data from vehicle and each drug dose tested were log-transformed and fitted using GraphPad Prism's 7 sigmoidal dose-response equation: $\mathrm{Y}=$ Bottom $+($ Top - Bottom $) /\left(1+10^{\wedge}((\operatorname{LogEC} 50-\mathrm{X}) \times\right.$ HillSlope $\left.)\right)$. The criteria for drug substitution used here were similar to those originally proposed by Colpaert (1987) and by Fiorella et al. (1995) and were determined by individual one-way ANOVAs followed by Sidak's post-hoc tests. Thus, the tested dose could engender a level of drug-appropriate responding: a) significantly different from that produced by vehicle condition and not significantly different from the drug (defined as full substitution), or, b) significantly different from that produced by drug and not significantly different from the vehicle training condition (defined as no substitution), or, c) significantly different from both vehicle and drug training conditions (defined as partial substitution).

Individual ANOVAs (GraphPad Prism's 7) were also used to assess the effects of tested compounds on the response rate, i.e., the number of nose-pokes recorded per 2.5-min during extinction and testing sessions.

\section{Results}

\subsection{Chemical purities of ketamines}

Yokoyama et al. (2009) reported specific optical rotation for $(S)$-ketamine $\cdot \mathrm{HCl}:[\alpha]_{D}^{20}=$ +91.7 (c 2.00, $\mathrm{H}_{2} \mathrm{O}$ ). Our determinations display similar values for $(S)$-ketamine $\cdot \mathrm{HCl}:[\alpha]_{D}^{23}$ $=+93.2\left(c 1.08, \mathrm{H}_{2} \mathrm{O}\right)$, HPLC (free amine) ee > 99\%, (Chiralcel OD-H, hexane $/ \mathrm{i}-\mathrm{PrOH}$ 95:5, flow rate $0.5 \mathrm{ml} / \mathrm{min}, \lambda 254 \mathrm{~nm}): \mathrm{t}_{R}=19.3 \mathrm{~min}(S)$, (racemate: $\mathrm{t}_{R}=16.7 \mathrm{~min}(R), \mathrm{t}_{R}=19.6$ $\min (S))$. For $(R)$-ketamine $\cdot \mathrm{HCl}$, we observed the following values: $[\alpha]_{D}^{24}=-91.2(c 0.72$, $\mathrm{H}_{2} \mathrm{O}$ ); HPLC (free amine): ee > 99\%, (Chiralcel OD-H, hexane/i-PrOH 95:5, flow rate 0.5 $\mathrm{ml} / \mathrm{min}, \lambda 254 \mathrm{~nm}): \mathrm{t}_{R}=16.7 \min (R)$, (racemate: $\left.\mathrm{t}_{R}=16.7 \mathrm{~min}(R), \mathrm{t}_{R}=19.6 \min (S)\right)$. Overall, both specific rotations and HPLC analysis show that all of the ketamine forms 

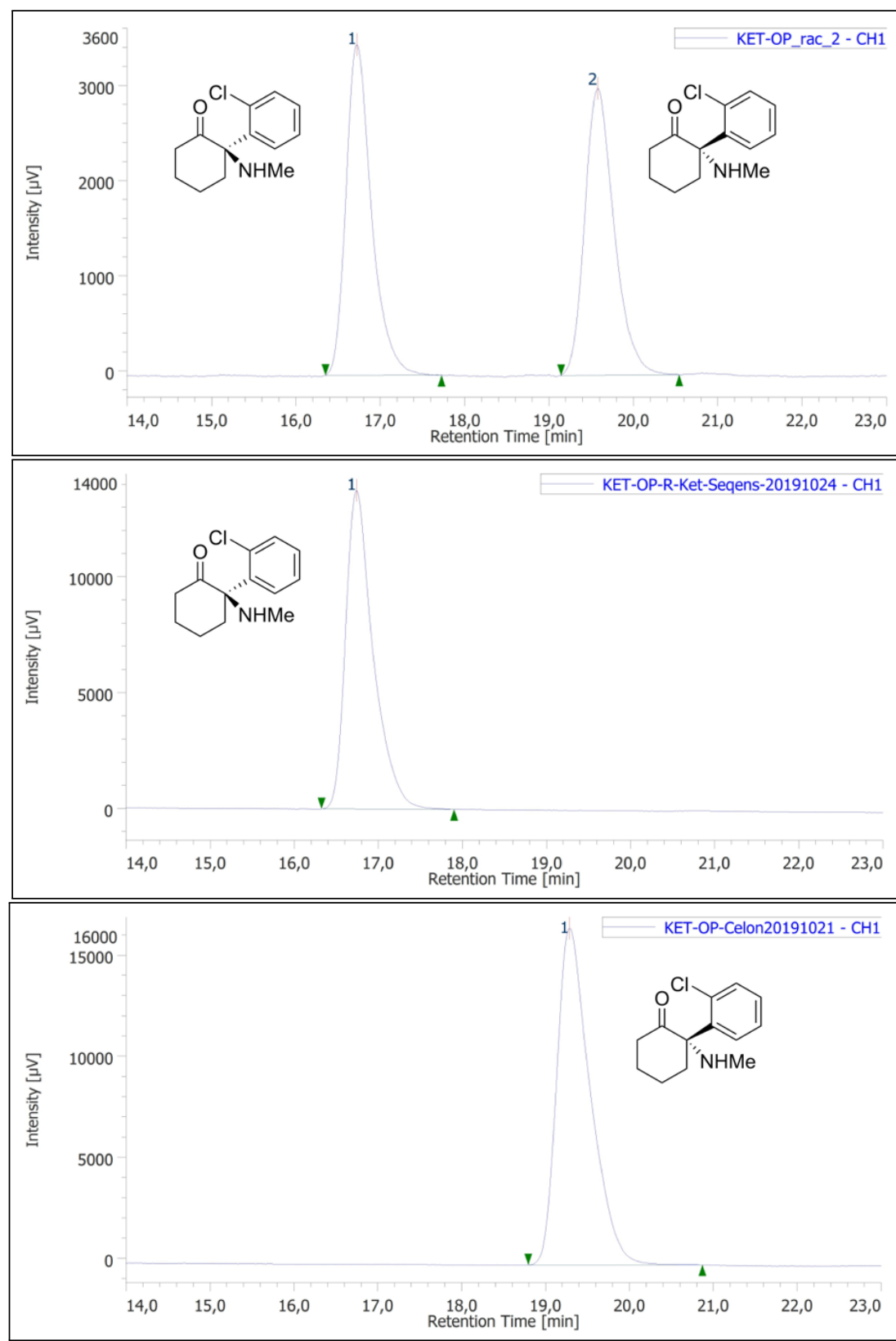

FIGURE 1. Determination of enantiopurity of $(R, S)$-ketamine (Vetoquinol Biowet, Gorzow Wielkopolski, Poland; top), $(R)$-ketamine (Seqens, Germany; middle), and $(S)$-ketamine (Celon Pharma, Warsaw, Poland; bottom).

we used in this study were optically pure with enantiomeric excess $>99 \%$. No impurities were found to be present in the samples. Fig. 1 shows chromatograms for the ketamine forms studied. 


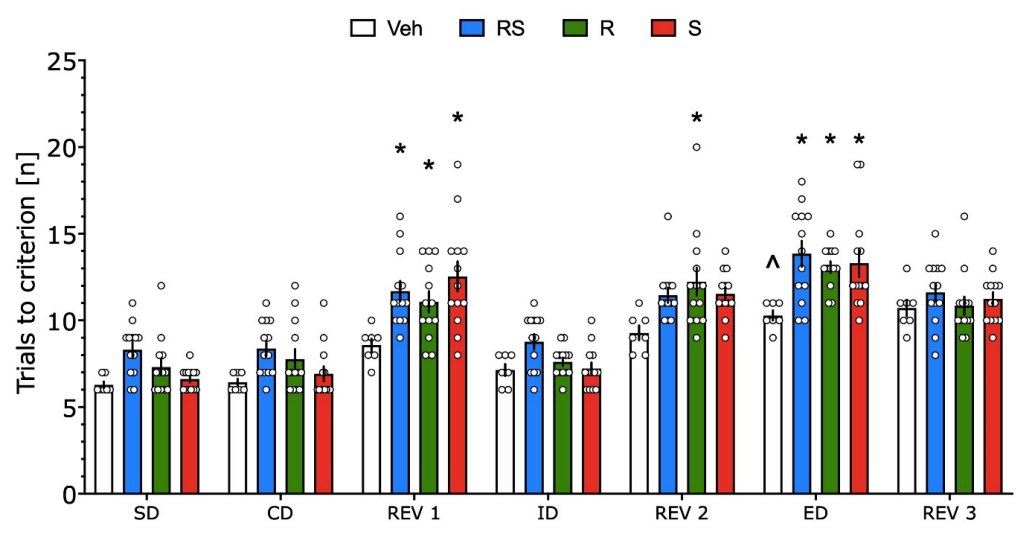

FIGURE 2. Effects of $(R, S)$ - $(R)$ - and $(S)$-ketamine, all at $10 \mathrm{mg} / \mathrm{kg}, \mathrm{SC}, 1 \mathrm{~h}$ prior to testing, on trials to criterion (TTC) in the attentional set shifting task (ASST) in rats. Data are presented as mean \pm SEM. The number of rats tested was $7,13,13$ and 13 for vehicle, $(R, S)$ - $(R)$ - and $(S)$-ketamine, respectively. Symbols: * $\mathrm{P}<0.05$ vs. vehicle at a given phase, ${ }^{\wedge} \mathrm{P}<0.05$ vs. vehicle's ID phase.

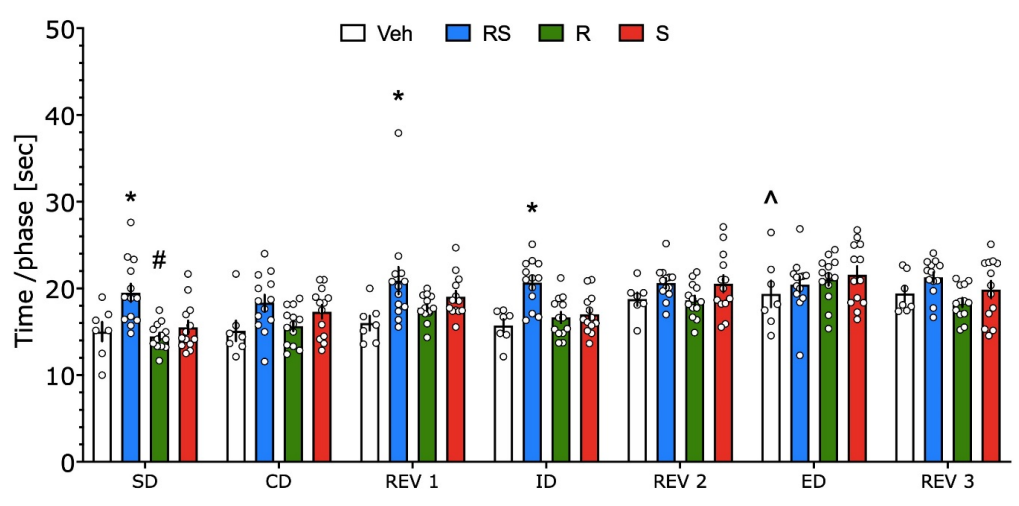

FIGURE 3. Effects of $(R, S)$ - $(R)$ - and $(S)$-ketamine on time/measure in the attentional set shifting task (ASST) in rats. Symbols: ${ }^{*} \mathrm{P}<0.05$ vs. vehicle at a given phase, \# $\mathrm{P}<0.05$ vs. $(R, S)$-ketamine at SD phase, ${ }^{\wedge} \mathrm{P}<0.05$ vs. vehicle's ID phase. Drug doses were $10 \mathrm{mg} / \mathrm{kg}, \mathrm{SC}, 1 \mathrm{~h}$ prior to testing. For other details, see the Legend to Fig. 2.

\subsection{ASST}

As shown on Fig. 2, both the specific treatment and the phase of the experiment affected trials to criterion (TTC): $F(18,252)=1.857 ; \mathrm{P}<0.025$. All 3 compounds increased the TTC measure, particularly at the ED and Reversal 1 discrimination phase; $(R)$-ketamine also increased TTC in the Reversal 2 discrimination (all $\mathrm{P}<0.05$ ).

Fig. 3 demonstrates that the specific treatment and phase of experiment also affected the time/phase measure: $\mathrm{F}(18,252)=2.016 ; \mathrm{P}<0.01$. However, only $(R, S)$-ketamine prolonged the mean time to complete SD, Reversal 1 and ID phases (all $\mathrm{P}<0.05$ ). 
A

$(R, S)$-ketamine
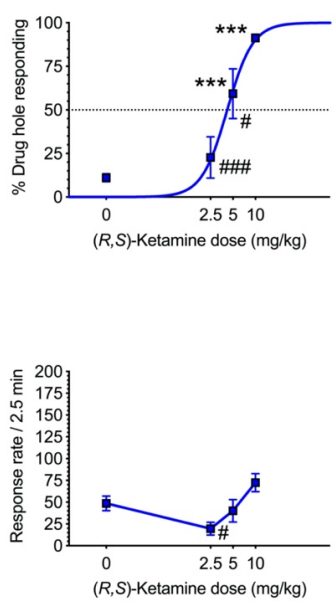

B
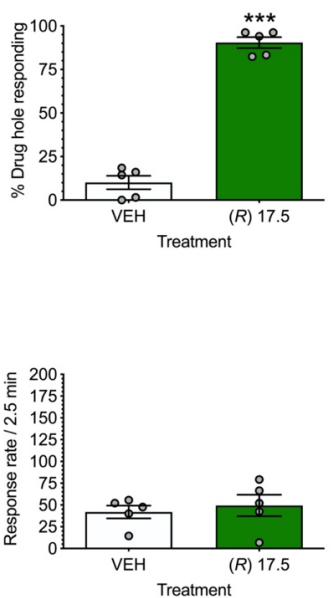

C

(S)-ketamine
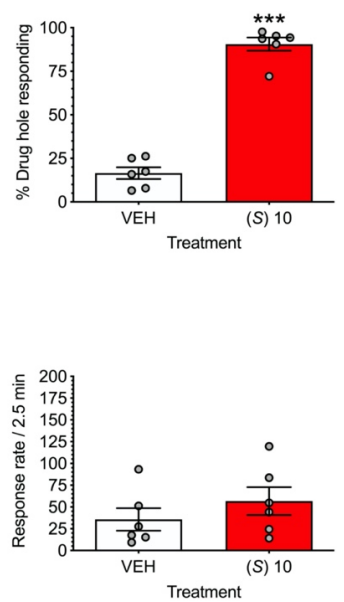

FIGURE 4. A. Dose-effect curve for $(R, S)$-ketamine in rats trained to discriminate $(R, S)$-ketamine $(10 \mathrm{mg} / \mathrm{kg})$ from vehicle. Top panel: \% drug-appropriate responses; bottom panel: response rate. Dotted line represents $50 \%$ accuracy. Ns for $(R, S)$-ketamine at doses $0,2.5,5$ and $10 \mathrm{mg} / \mathrm{kg}$ were 9, 4, 5 and 9, respectively. B. Effects of $17.5 \mathrm{mg} / \mathrm{kg}(R)$-ketamine in rats trained to discriminate $(R)$-ketamine $(17.5 \mathrm{mg} / \mathrm{kg})$ from vehicle. Top panel: \% drug-appropriate responses; Bottom panel: response rate. Ns for vehicle and for $(R)$-ketamine were 5 . C. Effects of $10 \mathrm{mg} / \mathrm{kg}(S)$-ketamine in rats trained to discriminate $(S)$-ketamine $(10 \mathrm{mg} / \mathrm{kg})$ from vehicle. Top panel: \% drug-appropriate responses; Bottom panel: response rate. $\mathrm{N}$ for vehicle and for $(S)$-ketamine were 6 . Data are shown as mean \pm SEM. Symbols: ${ }^{* * *} \mathrm{P}<0.001$ vs. respective vehicle, \# $\mathrm{P}<0.05$ and \#\#\# $\mathrm{P}<0.001$ vs. $(R, S)$-ketamine training dose.

\subsection{Drug discrimination}

\subsubsection{Acquisition}

Rats in the $(R, S)$ and $(S)$-ketamine-trained groups acquired full discriminative control by day 50 . Since the $(R)$-ketamine discrimination was not maintained up to day 50 , the dose was increased to $17.5 \mathrm{mg} / \mathrm{kg}$ and this dose escalation re-invigorated discriminative performances. At day 60 , discrimination accuracy was sufficient $(\geqslant 85 \%)$ to start substitution testing. Nonetheless, at day 80 due to the insufficient stimulus control $(<85 \%$ of accuracy), we eliminated 2,3 , and 3 animals from $(R, S)$-, $(R)$ - and $(S)$-ketamine groups, respectively, and at day 102, an additional one animal from the $(R)$-ketamine group.

\subsubsection{Discriminative control by (R)-, (S)-, and (R,S)-ketamine}

Fig $4 \mathrm{~A}$ shows the dose-response curve for $(R, S)$-ketamine in rats trained to discriminate $(R, S)$-ketamine $(10 \mathrm{mg} / \mathrm{kg})$ from vehicle. Oneway ANOVA documented a significant effect of $(R, S)$-ketamine dose: $\mathrm{F}(3,23)=38.46$; $\mathrm{P}<0.05$. As compared with vehicle, doses of 5 and $10 \mathrm{mg} / \mathrm{kg}$ resulted in higher $(R, S)$-ketamine-like hole responding; doses of 2.5 and $5 \mathrm{mg} / \mathrm{kg}$ resulted in lower percentages than with the training dose of $(R, S)$-ketamine (10 $\mathrm{mg} / \mathrm{kg})$. For $(R, S)$-ketamine, the ED50 with 95\% confidence intervals was $4.19(3.38-5.20)$ $\mathrm{mg} / \mathrm{kg}$. $(R, S)$-ketamine doses also affected response rate: $\mathrm{F}(3,23)=4.0 ; \mathrm{P}<0.05$ and $(R, S)$ ketamine at $2.5 \mathrm{mg} / \mathrm{kg}$ reduced response rates as compared to the training dose but not as compared to its vehicle.

When the training dose of $(R)$-ketamine was tested in rats trained to discriminate $(R)$ ketamine $(17.5 \mathrm{mg} / \mathrm{kg})$ from vehicle, full substitution of $(R)$-ketamine was achieved $(t=$ 16 ; $d f=8 ; \mathrm{P}<0.001$; Fig. 4B top). Response rates were not significantly different between 

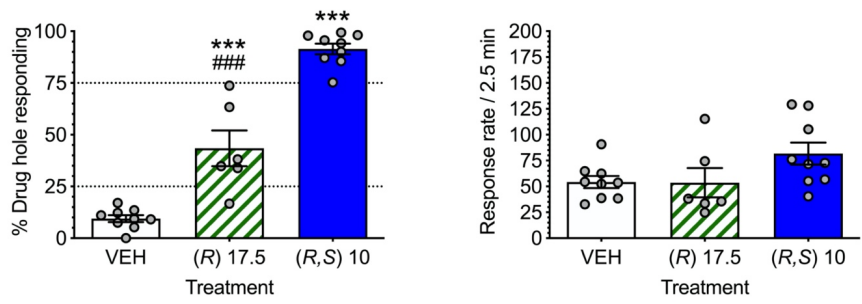

FIGURE 5. In $(R, S)$-ketamine-trained rats, $(R)$-ketamine partially substituted for the training dose of $10 \mathrm{mg} / \mathrm{kg}(R, S)$-ketamine. $\mathrm{N}$ for vehicle, $(R)$-ketamine $(17.5)$ and $(R, S)$-ketamine $(10 \mathrm{mg} / \mathrm{kg})$ was 9, 6 and 9, respectively. Symbols: *** $\mathrm{P}<0.001$ vs. vehicle, \#\#\# $\mathrm{P}<0.001$ vs. $(R, S)$-ketamine training dose. Dotted lines represent 25 and $75 \%$ accuracy.
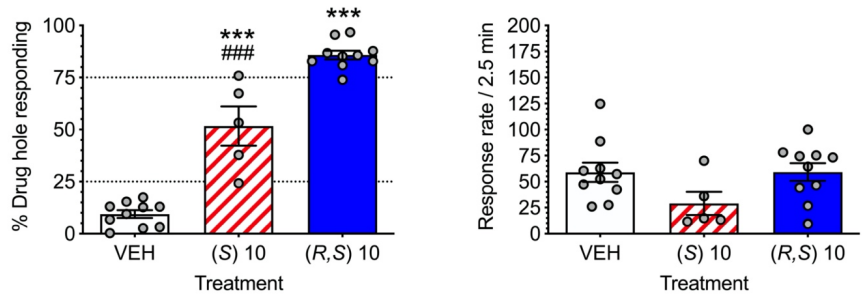

FIGURE 6. In $(R, S)$-ketamine-trained rats, $(S)$-ketamine partially substituted for the training dose of $10 \mathrm{mg} / \mathrm{kg}(R, S)$-ketamine. $\mathrm{N}$ for vehicle, $(S)$-ketamine $(10 \mathrm{mg} / \mathrm{kg})$ and $(R, S)$-ketamine $(10 \mathrm{mg} / \mathrm{kg})$ was 10,5 and 10 , respectively. Symbols: ${ }^{* *} \mathrm{P}<0.001$ vs. vehicle, \#\#\# $\mathrm{P}<0.001$ vs. $(R, S)$-ketamine training dose. Dotted lines represent 25 and $75 \%$ accuracy.

vehicle and $(R)$-ketamine $(t=0.51 ; d f=8$; NS; Fig. 4B bottom). Reduction in the number of rats in the $(R)$-training group from attrition described above did not allow fully powered data to evaluate dose-response relationships in this group.

When the training dose of $(S)$-ketamine was tested in rats trained to discriminate $(S)$ ketamine $(10 \mathrm{mg} / \mathrm{kg})$ from vehicle, full substitution of $(S)$-ketamine was achieved $(t=$ 14.56; $d f=10 ; \mathrm{P}<0.001$; Fig. $4 \mathrm{C}$ top). Response rates were not significantly different between vehicle and $(R)$-ketamine $(t=1.02 ; d f=10$; NS; Fig. 4C bottom). Reduction in the number of rats in the $(S)$-training group from attrition described above did not allow fully-powered data to evaluate dose-response relationships in this group.

In all three groups of rats, when the training dose was tested, the variability in responding was very low, with all rats achieving high levels of discriminative control (Fig. 4).

\subsubsection{Substitution of each isomeric form}

In $(R, S)$-ketamine-trained rats, $(R)$-ketamine partially substituted for the training dose of $10 \mathrm{mg} / \mathrm{kg}(R, S)$-ketamine: $\mathrm{F}(2,21)=110.0 ; \mathrm{P}<0.001$. In this experiment $(R)$ ketamine did not produce $\geqslant 75 \%$ drug-appropriate response in any of the 6 rats tested; in contrast, none of the 9 rats tested with the training dose of $(R, S)$-ketamine exhibited $\leqslant 75 \%$ drug-appropriate responses. Response rates were not significantly different from one another in this experiment: $\mathrm{F}(2,21)=2.715$; $\mathrm{P}=0.08$ (Fig. 5). Partial substitution occurred despite the fact that $(R)$-ketamine was given at dose exceeding the $5 \mathrm{mg} / \mathrm{kg}$ of the $(R)$-enantiomer delivered by the $10 \mathrm{mg} / \mathrm{kg}(R, S)$-ketamine training dose.

Similarly, $(S)$-ketamine also partially substituted for the training dose of $(R, S)$ ketamine: $\mathrm{F}(2,22)=128.8 ; \mathrm{P}<.001$. In this experiment $(S)$-ketamine produced $\geqslant 75 \%$ 

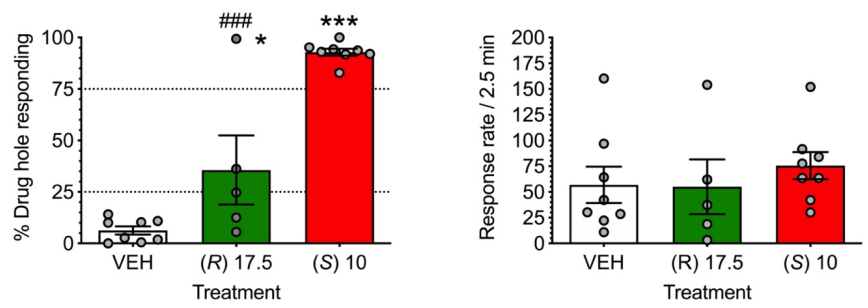

FIGURE 7. (R)-ketamine did not fully substitute for the training dose of $(S)$-ketamine in $(S)$-ketamine-trained rats. Ns for vehicle and $(S)$-ketamine were 8 , whereas 5 rats were tested with (R)-ketamine (17.5 mg/kg). Symbols: * $\mathrm{P}<0.05$, *** $\mathrm{P}<0.001$ vs. vehicle, \#\#\# $\mathrm{P}<0.001$ vs. training dose of $(S)$-ketamine. Dotted lines represent 25 and $75 \%$ accuracy.

drug-appropriate response only in one of the 5 rats tested; in contrast, only one of the 10 rats tested with the training dose of $(R, S)$-ketamine exhibited $\leqslant 75 \%$ drug-appropriate responses. Response rates were not significantly different from one another in this experiment: $F(2,22)=2.33$, NS (Fig. 6).

$(R)$-ketamine did not fully substitute for the training dose of $(S)$-ketamine in $(S)$ ketamine-trained rats (Fig. 7): $\mathrm{F}(2,18)=46.01 ; \mathrm{P}<0.001$. Only 1 rat of the 5 tested showed outlier responses of $\geqslant 75 \%(S)$-ketamine-appropriate responses. In contrast, $0 / 8$ rats given $10 \mathrm{mg} / \mathrm{kg}(S)$-ketamine demonstrated stimulus control $\leqslant 75 \%$. There were no significant differences in rates of responding produced by these compounds: $F(2,18)=$ 0.41, NS (Fig. 7).

Partial substitution of $(R)$-ketamine occurred despite the fact that this enantiomer was tested at the $17.5 \mathrm{mg} / \mathrm{kg}$ dose, exceeding those delivered by the $10 \mathrm{mg} / \mathrm{kg}$ of $(R, S)$ ketamine (Fig. 5) and of (S)-ketamine (Fig. 7) training doses.

\section{Discussion}

Preclinical and clinical data have shown that there are quantitative and qualitative differences in the pharmacological effects of $(R)$ - vs $(S)$-ketamine (summarized in the Introduction). In line with our previously reported data (Nikiforuk et al. 2010), (R,S)ketamine disrupted rats' ASST performance. Similar effects were demonstrated for $(R)$ and $(S)$-ketamine in the present study, providing the first report of the cognitive impact of ketamine enantiomers in rodents. Specifically, all compounds induced deficits in reversal learning and extra-dimensional set-shifting stages as measured by the trials to criterion parameter. However, in contrast to $(R)$ - and $(S)$-ketamine, $(R, S)$-ketamine prolonged the time to complete a single trial during early stages of the ASST. This effect may be interpreted as an increased reaction time, suggesting that the racemate may have more detrimental effects on cognition than the individual enantiomers. In line with these data, ketamine isomers induce less cognitive impairment than racemic ketamine in human volunteers (Pfenninger et al. 2002). Nevertheless, the increased time to complete ASST stages after $(R, S)$-ketamine might also be interpreted as unspecific sideeffects related to motor or motivational impairments. Additional experiments will be required to fully appreciate the behavioral mechanisms associated with the differential pharmacology reported here. 
TABLE 1. Summary of the effects of different ketamine forms in rats trained to discriminate each drug form from vehicle. NT: not tested due to insufficient N.

\begin{tabular}{|l|l|l|l|l|}
\hline Trained to & \multicolumn{4}{|c|}{ Tested with } \\
\hline & $(R, S) 10$ & $(R) 17.5$ & $(S) 10$ & \\
\hline $10 \mathrm{mg} / \mathrm{kg}$ of $(R, S)$-ketamine & full & partial & partial & Figure 4, 5 \& 6 \\
\hline $17.5 \mathrm{mg} / \mathrm{kg}$ of $(R)$-ketamine & NT & full & NT & Figure 4 \\
\hline $10 \mathrm{mg} / \mathrm{kg}$ of $(S)$-ketamine & NT & partial & full & Figure 7 \\
\hline
\end{tabular}

We used drug discrimination methods in rats to further evaluate the potential for the ketamine isomers to produce distinct subjective responses (see justification for drug discrimination methods for this purpose in the Introduction). We judged these potential differences by measuring the degree to which one isomer substituted for the others (see Colpaert (1987)). In order to test the hypothesis that the enantiomers of ketamine produce distinct subjective responses in humans as suggested by the literature (see Introduction), rats were trained to discriminate either $10 \mathrm{mg} / \mathrm{kg}(R, S)$-ketamine, $10 \mathrm{mg} / \mathrm{kg}$ $(S)$-ketamine, or $17.5 \mathrm{mg} / \mathrm{kg}(R)$-ketamine from saline. Drug substitution tests, summarized in Table 1, were conducted to ascertain the degree to which each isomer produced comparable discriminative stimulus effect to that of the training dose.

Ketamine is a racemic mixture of equal parts $(S)$-ketamine and $(R)$-ketamine. Therefore, in a discrimination based upon $10 \mathrm{mg} / \mathrm{kg}(R, S)$-ketamine, this dose would be pharmacologically equivalent to $5 \mathrm{mg} / \mathrm{kg}$ of each isomer. However, neither $(R)$ - (Fig. 5$)$ nor $(S)$-ketamine (Fig. 6) fully substituted for the training dose of $(R, S)$-ketamine. The partial substitution was found even though doses higher than $5 \mathrm{mg} / \mathrm{kg}$ of each compound were tested. Since drug substitutions under these conditions are dose-dependent (Balster \& Willets (1988); Brady \& Balster (1982); Holtzman (1985); see also Fig. 4), then the test for discriminative stimulus equivalence used here was a best-case scenario. However, higher doses of each isomer (not tested here) might have substituted fully although the interpretation of such a finding (given the $50 \%$ dose mixture of the racemate) would require additional data to understand.

We are aware of only a few prior reports evaluating the question of whether the isomers of ketamine produce similar or disparate discriminative stimulus effects. However, all studies utilized phencyclidine (PCP), not ketamine as a training drug. In these studies, both $(S)$ - and $(R)$ - ketamine fully substituted for phencyclidine (PCP) (Brady \& Balster 1982; Zukin et al. 1984) as did the racemic mixture (Holtzman 1985) indicating that the two isomers produce equivalent contributions to the discriminative stimulus effects of PCP. In both reports, $(R)$-ketamine was about $2 \times$ less potent than $(S)$-ketamine in producing discriminative stimulus effects comparable to PCP. These potency differences were also found in the present study although the lower potency of $(R)$-ketamine in the current data set was biased somewhat by the higher training dose of $(R)$-ketamine compared to that used for the $(S)$-ketamine drug discrimination $(17.5 \mathrm{vs} 10 \mathrm{mg} / \mathrm{kg}$, respectively).

That $(R)$-ketamine displayed unique discriminative stimulus effects in rats is further demonstrated by the relatively difficulty in maintaining the drug discrimination. Drug discrimination at $10 \mathrm{mg} / \mathrm{kg}$, sufficient for the racemate and for $(S)$-ketamine, was not sufficient to maintain discriminative performances in $(R)$-ketamine-trained rats. Increasing the dose of $(R)$-ketamine to $17.5 \mathrm{mg} / \mathrm{kg}$ re-invigorated discriminative performances. Nonetheless, the ability of $(R)$-ketamine to maintain accurate responding even at this dose increase was not perfect. $(R)$-ketamine also was differentiated from $(S)$-ketamine in the rats trained to discriminate $(S)$-ketamine from vehicle. In these rats, $(R)$-ketamine did not display $(S)$-ketamine-like discriminative stimulus effects (Fig. 7, Table 1). Such 
findings of subjective effect differences in the ketamine enantiomers is mirrored in the few clinical reports in which comparisons have been made (see Introduction).

It has been long thought that ketamine produces its primary pharmacological effects through blockade of the NMDA receptor ion channel (Anis et al. 1983). Indeed, this mechanism is generally consistent with findings in the drug discrimination literature where ketamine and PCP, for example, share common discriminative stimulus effects (Brady \& Balster 1982; Holtzman 1985; Zukin et al. 1984). Potency estimates of $(R)$ - and $(S)$-ketamine for the NMDA receptor ion channel (see Zanos et al. 2018, for a comprehensive review) have demonstrated that $(S)$-ketamine is about 4 times more potent than (R)-ketamine (Ebert et al. 1997; Moaddel et al. 2013; Zukin et al. 1984). It is unlikely that a potency difference could account for the lack of full substitution reported in this study or the lack of substitution of $(R)$-ketamine for $(S)$-ketamine reported here. For example, memantine fully substitutes for the discriminative stimulus of the potent NMDA receptor antagonist dizocilpine despite being 180-fold lower in potency (GeterDouglass \& Witkin 1999). Nonetheless, a full test of the NMDA receptor hypothesis in these drug discriminations would require additional scrutiny. In recent years, data have accumulated to suggest alternatives to the NMDA receptor hypothesis (see Yang et al. 2019, and Zanos et al. 2019).

The present findings demonstrate that the different isomeric forms of ketamine produce overlapping but not identical mechanisms of action. Future research will be needed to identify the underlying neurobiological substrates mediating the differential pharmacology observed. Results of this inquiry should lead to better control of patient response and side-effect profile in next generation drugs. The fact that $(R)$-ketamine was effective in treatment-resistant depressed patients, albeit in a small open-label study, and produced very little in the way of dissociative effects (Leal et al. 2020) suggests that one can create efficacy with reduced side-effects. Ketamine is a drug of abuse (see Zanos et al. 2018) and drug discrimination commonalities suggest abuse potential (see Klein et al. 1999; Schuster \& Johanson 1988). The data from the present study showing that $(R)$-ketamine does not fully substitute for $(R, S)$ ketamine and also does not fully substitute in rats discriminating $(S)$-ketamine provides some additional suggestion that $(R)$-ketamine might have a reduced abuse liability. Such findings are also consistent with the differential ability of $(R)$ - and $(S)$-ketamine to produce conditioned place preference, another model used to predict abuse potential (Yang et al. 2015).

Taken as a whole, the present data indicate that racemic ketamine produces more severe cognitive impairment than its enantiomers although the nature of these cognitive, motor, and/or motivational differences need detailed experimental scrutiny. In addition, we report that racemic ketamine and its isomers share overlapping but not isomorphic discriminative stimulus effects in rats. The present set of experiments is the first to report data on cognition testing with the ketamine isomers in rats and in rats trained to discriminate the isomers of ketamine. Additional work is needed to fully understand the mechanisms underlying the discriminative control produced by these isomers (e.g., which NMDA ion-channel blockers might differentially substitute, and which non-NMDA receptor-linked compounds might differentially substitute for each isomeric drug form). At present, the data predict a distinct subjective response of $(R)$ vs. $(S)$-ketamine in humans as has been already hinted at by literature reports.

\section{Acknowledgements}

This study was supported by the Statutory Activity of the Maj Institute of Pharmacology, Polish Academy of Sciences, Kraków, Poland. Shaun Yon-Seng Khoo was supported 
by a postdoctoral fellowship from the Fonds de Recherche du Québec - Santé. We are grateful to Kyle Kaniecki and Perception Neuroscience for their contribution of some of the $(R)$-ketamine used in this study.

\section{REFERENCES}

Anis, N. A., Berry, S. C., Burton, N. R. \& Lodge, D. 1983 The dissociative anaesthetics, ketamine and phencyclidine, selectively reduce excitation of central mammalian neurones by N-methylaspartate. Br. J. Pharmacol 79 (2), 565-575. doi: 10.1111/j.1476-5381.1983.tb11031.x.

Balster, R. L. \& Willets, J. 1988 Receptor mediation of the discriminative stimulus properties of phencyclidine and sigma-opioid agonists. In Transduction Mechanisms of Drug Stimuli (ed. F.C. Colpaert \& R. L. Balster), pp. 122-135. Berlin: Springer-Verlag. doi: 10.1007/978-3-64273223-2_1.

Banov, M. D., Young, J. R., Dunn, T. \& Szabo, S. T. 2019 Efficacy and safety of ketamine in the management of anxiety and anxiety spectrum disorders: a review of the literature. CNS Spectr. pp. 1-12. doi: 10.1017/S1092852919001238.

Berman, R. M., Cappiello, A., Anand, A., Oren, D. A., Heninger, G. R., Charney, D. S. \& Krystal, J. H. 2000 Antidepressant effects of ketamine in depressed patients. Biol. Psychiatry 47 (4), 351-354. doi: 10.1016/s0006-3223(99)00230-9.

Birrell, J. M. \& Brown, V. J. 2000 Medial frontal cortex mediates perceptual attentional set shifting in the rat. J. Neurosci. 20 (11), 4320-4324. doi: 10.1523/jneurosci.20-11-04320.2000.

Bolin, B. L., Alcorn, J. L., Reynolds, A. R., Lile, J. A. \& Rush, C. R. 2016 Human drug discrimination: A primer and methodological review. Exp. Clin. Psychopharmacol. 24 (4), 214-28. doi: 10.1037/pha0000077.

Brady, K. T. \& Balster, R. L. 1982 Discriminative stimulus properties of ketamine stereoisomers in phencyclidine-trained rats. Pharmacol. Biochem. Behav. 17 (2), 291-5. doi: 10.1016/00913057(82)90083-1.

Burgdorf, J., Zhang, X. L., Nicholson, K. L., Balster, R. L., David, Leander J., Stanton, P. K., Gross, A. L., Kroes, R. A. \& Moskal, J. R. 2013 GLYX-13, a NMDA receptor glycine-site functional partial agonist, induces antidepressant-like effects without ketamine-like side effects. Neuropsychopharmacol. 38 (5), 729-742. doi: 10.1038/npp.2012.246.

Chang, L., Zhang, K., Pu, Y., Qu, Y., Wang, S. M., Xiong, Z., Ren, Q., Dong, C., Fujita, Y. \& Hashimoto, K. 2019 Comparison of antidepressant and side effects in mice after intranasal administration of (R,S)-ketamine, (R)-ketamine, and (S)-ketamine. Pharmacol. Biochem. Behav. 181, 53-59. doi: 10.1016/j.pbb.2019.04.008.

Chiamulera, C., Armani, F., Mutti, A. \& Fattore, L. 2016 The ketamine analogue methoxetamine generalizes to ketamine discriminative stimulus in rats. Behav. Pharmacol. 27 (2-3 Spec Issue), 204-10. doi: 10.1097/FBP.0000000000000221.

Colpaert, F.C. 1987 Drug Discrimination: Methods of Manipulation, Measurement, and Analysis. In Methods of Assessing the Reinforcing Properties of Abused Drugs (ed. M. A. Bozarth), pp. 341372. New York: Springer Verlag. doi: 10.1007/978-1-4612-4812-5_17.

Cristea, I. A. \& Naudet, F. 2019 US Food and Drug Administration approval of esketamine and brexanolone. Lancet Psychiatry 6 (12), 975-977. doi: 10.1016/s2215-0366(19)30292-5.

Dakwar, E., Levin, F., Hart, C. L., Basaraba, C., Choi, J., Pavlicova, M. \& Nunes, E. V. 2020 A single ketamine infusion combined with motivational enhancement therapy for alcohol use disorder: A randomized midazolam-controlled pilot trial. Am. J. Psychiatry 177 (2), 125133. doi: 10.1176/appi.ajp.2019.19070684.

De Vry, J. \& Jentzsch, K. R. 2003 Role of the NMDA receptor NR2B subunit in the discriminative stimulus effects of ketamine. Behav. Pharmacol. 14 (3), 229-235. doi: 10.1097/00008877200305000-00007.

Domino, E. F., Chodoff, P. \& Corssen, G. 1965 Pharmacologic effects of CI-581, a new dissociative anesthetic, in man. Clin. Pharmacol. Ther. 6, 279-91. doi: 10.1002/cpt196563279.

Ebert, B., Mikkelsen, S., Thorkildsen, C. \& Borgbjerg, F. M. 1997 Norketamine, the main metabolite of ketamine, is a non-competitive NMDA receptor antagonist in the rat cortex and spinal cord. Eur. J. Pharmacol. 333 (1), 99-104. doi: 10.1016/S0014-2999(97)01116-3.

Extance, K. \& Goudie, A. J. 1981 Inter-animal olfactory cues in operant drug discrimination procedures in rats. Psychopharmacol. 73 (4), 363-371. doi: 10.1007/bf00426467. 
Fiorella, D., Rabin, R. A. \& Winter, J. C. 1995 Role of 5-HT2a and 5-HT2c receptors in the stimulus effects of hallucinogenic drugs II: reassessment of LSD false positives. Psychopharmacol. 121 (3), 357-363. doi: 10.1007/bf02246075.

Fukumoto, Kenichi, Toki, Hidetoh, Iijima, Michihiko, Hashihayata, Takashi, Yamaguchi, Junichi, Hashimoto, Kenji \& Chaki, Shigeyuki 2017 Antidepressant potential of (R)-ketamine in rodent models: Comparison with (S)-ketamine. J. Pharmacol. Exp. Ther. 361 (1), 9-16. doi: 10.1124/jpet.116.239228.

Geter-Douglass, B. \& Witkin, J. M. 1999 Behavioral effects and anticonvulsant efficacies of lowaffinity, uncompetitive NMDA antagonists in mice. Psychopharmacol. 146 (3), 280-289. doi: $10.1007 / \mathrm{s} 002130051118$.

Glennon, R. A., Young, R. \& Rosecrans, J. A. 1983 Antagonism of the effects of the hallucinogen DOM and the purported 5-HT agonist quipazine by 5-HT2 antagonists. Eur. J. Pharmacol. 91 (2-3), 189-96. doi: 10.1016/0014-2999(83)90464-8.

Gresch, Paul J., Barrett, Robert J., Sanders-Bush, Elaine \& Smith, Randy L. 2007 5Hydroxytryptamine (Serotonin)2A Receptors in Rat Anterior Cingulate Cortex Mediate the Discriminative Stimulus Properties of d-Lysergic Acid Diethylamide. J. Pharmacol. Exp. Ther. 320 (2), 662. doi: 10.1124/jpet.106.112946.

Hashimoto, K. 2019 Rapid-acting antidepressant ketamine, its metabolites and other candidates: A historical overview and future perspective. Psychiatry Clin. Neurosci. 73 (10), 613-627. doi: 10.1111/pcn.12902.

Hashimoto, K., Kakiuchi, T., Ohba, H., Nishiyama, S. \& Tsukada, H. 2017 Reduction of dopamine D2/3 receptor binding in the striatum after a single administration of esketamine, but not R-ketamine: a PET study in conscious monkeys. Eur. Arch. Psychiatry Clin. Neurosci. 267 (2), 173-176. doi: 10.1007/s00406-016-0692-7.

Holtzman, S. G. 1985 Drug discrimination studies. Drug Alcohol Depend. 14 (3-4), 263-82. doi: 10.1016/0376-8716(85)90061-4.

Ji Kwon, N. \& Han, E. 2019 A review of drug abuse in recently reported cases of driving under the influence of drugs (DUID) in Asia, USA, and Europe. Forensic Sci Int 302, 109854. doi: 10.1016/j.forsciint.2019.06.012.

Jones, J. L., Mateus, C. F., Malcolm, R. J., Brady, K. T. \& Back, S. E. 2018 Efficacy of ketamine in the treatment of substance use disorders: A systematic review. Front. Psychiatry 9, 277. doi: $10.3389 /$ fpsyt.2018.00277.

Klein, M., Calderon, S. \& Hayes, B. 1999 Abuse liability assessment of neuroprotectants. Ann. N. Y. Acad. Sci. 890, 515-25. doi: 10.1111/j.1749-6632.1999.tb08033.x.

Kos, T., Popik, P., Pietraszek, M., Schafer, D., Danysz, W., Dravolina, O., Blokhina, E. A., Galankin, T. \& Bespalov, A. Y. 2006 Effect of 5-HT3 receptor antagonist MDL 72222 on behaviors induced by ketamine in rats and mice. Eur. Neuropsychopharmacol. 16 (4), 297-310. doi: 10.1016/j.euroneuro.2005.10.001.

Krystal, J. H., Karper, L. P., Seibyl, J. P., Freeman, G. K., Delaney, R., Bremner, J. D., Heninger, G. R., Bowers, M. B. \& Charney, D. S. 1994 Subanesthetic effects of the noncompetitive NMDA antagonist, ketamine, in humans. Psychotomimetic, perceptual, cognitive, and neuroendocrine responses. Arch. Gen. Psychiatry 51 (3), 199-214. doi: 10.1001/archpsyc.1994.03950030035004.

Leal, G. C., Bandeira, I. D., Correia-Melo, F. S., Telles, M., Mello, R. P., Vieira, F., Lima, C. S., JesusNunes, A. P., Guerreiro-Costa, L. N. F., Marback, R. F., Caliman-Fontes, A. T., Marques, B. L. S., Bezerra, M. L. O., Dias-Neto, A. L., Silva, S. S., Sampaio, A. S., Sanacora, G., Turecki, G., Loo, C., Lacerda, A. L. T. \& Quarantini, L. C. 2020 Intravenous arketamine for treatment-resistant depression: open-label pilot study. Eur. Arch. Psychiatry Clin. Neurosci. doi: 10.1007/s00406-020-01110-5.

Liriano, F., Hatten, C. \& Schwartz, T. L. 2019 Ketamine as treatment for post-traumatic stress disorder: a review. Drugs Context 8, 212305. doi: 10.7573/dic.212305.

Mion, G. 2017 History of anaesthesia: The ketamine story - past, present and future. Eur. J. Anaesthesiol. 34 (9), 571-575. doi: 10.1097/EJA.0000000000000638.

Moaddel, R., Abdrakhmanova, G., Kozak, J., Jozwiak, K., Toll, L., Jimenez, L., Rosenberg, A., Tran, T., Xiao, Y., Zarate, C. A. \& Wainer, I. W. 2013 Sub-anesthetic concentrations of (R,S)ketamine metabolites inhibit acetylcholine-evoked currents in alpha7 nicotinic acetylcholine receptors. Eur. J. Pharmacol. 698 (1-3), 228-234. doi: 10.1016/j.ejphar.2012.11.023.

Nielsen, R. V., Fomsgaard, J. S., Nikolajsen, L., Dahl, J. B. \& Mathiesen, O. 2019 Intraoperative S- 
ketamine for the reduction of opioid consumption and pain one year after spine surgery: A randomized clinical trial of opioid-dependent patients. Eur. J. Pain 23 (3), 455-460. doi: 10.1002/ejp.1317.

Nikiforuk, A., Golembiowska, K. \& Popik, P. 2010 Mazindol attenuates ketamine-induced cognitive deficit in the attentional set shifting task in rats. Eur. Neuropsychopharmacol. 20 (1), 37-48. doi: 10.1016/j.euroneuro.2009.08.001.

Nugent, A. C., Ballard, E. D., Gould, T. D., Park, L. T., Moaddel, R., Brutsche, N. E. \& Zarate, C. A., Jr. 2019 Ketamine has distinct electrophysiological and behavioral effects in depressed and healthy subjects. Mol. Psychiatry 24 (7), 1040-1052. doi: 10.1038/s41380-018-0028-2.

Persson, J., Hasselström, J., Wiklund, B., Heller, A., Svensson, J. O. \& Gustafsson, L. L. 1998 The analgesic effect of racemic ketamine in patients with chronic ischemic pain due to lower extremity arteriosclerosis obliterans. Acta Anaesthesiol, Scand. 42 (7), 750-8. doi: 10.1111/j.1399-6576.1998.tb05317.x.

Persson, J., Hasselstrom, J., Maurset, A., Oye, I., Svensson, J. O., Almqvist, O., Scheinin, H., Gustafsson, L. L. \& Almqvist, O. 2002 Pharmacokinetics and non-analgesic effects of S- and R-ketamines in healthy volunteers with normal and reduced metabolic capacity. Eur. J. Clin. Pharmacol. 57 (12), 869-75. doi: 10.1007/s002280100353.

Pfenninger, E. G., Durieux, M. E. \& Himmelseher, S. 2002 Cognitive impairment after small-dose ketamine isomers in comparison to equianalgesic racemic ketamine in human volunteers. Anesthesiology 96 (2), 357-66. doi: 10.1097/00000542-200202000-00022.

Popik, P., Krawczyk, M., Kuziak, A., Bugno, R., Hogendorf, A., Staron, J. \& Nikiforuk, A. 2019 Serotonin type 5A receptor antagonists inhibit D-lysergic acid diethylamide discriminatory cue in rats. J. Psychopharmacol. 33 (11), 1447-1455. doi: 10.1177/0269881119867603.

Potasiewicz, Agnieszka, Golebiowska, Joanna, Popik, Piotr \& Nikiforuk, Agnieszka 2019 Procognitive effects of varenicline in the animal model of schizophrenia depend on $\alpha 4 \beta 2$ - and $\alpha$ 7-nicotinic acetylcholine receptors. J. Psychopharmacol. 33 (1), 62-73. doi: 10.1177/0269881118812097.

Preskorn, S., Macaluso, M., Mehra, D. O., Zammit, G., Moskal, J. R. \& Burch, R. M. 2015 Randomized proof of concept trial of GLYX-13, an N-methyl-D-aspartate receptor glycine site partial agonist, in major depressive disorder nonresponsive to a previous antidepressant agent. $J$. Psychiatr. Pract. 21 (2), 140-149. doi: 10.1097/01.pra.0000462606.17725.93.

Schuster, C. R. \& Johanson, C. E. 1988 Relationship between the discriminative stimulus properties and subjective effects of drugs. Psychopharmacol. Ser. 4, 161-75. doi: 10.1007/9783-642-73223-2_13.

Stadler, J. R., Caul, W. F. \& Barrett, R. J. 1999 Characterizing withdrawal in rats following repeated drug administration using an amphetamine-vehicle-haloperidol drag discrimination. Psychopharmacol. 143 (3), 219-226. doi: 10.1007/s002130050940.

Vollenweider, F. X., Leenders, K. L., Øye, I., Hell, D. \& Angst, J. 1997 Differential psychopathology and patterns of cerebral glucose utilisation produced by (S)- and (R)-ketamine in healthy volunteers using positron emission tomography (PET). Eur. Neuropsychopharmacol. 7 (1), 25-38. doi: 10.1016/S0924-977X(96)00042-9.

Witkin, J. M., Kranzler, J., Kaniecki, K., Popik, P., Smith, J. L., Hashimoto, K. \& Sporn, J. 2020 R-()-ketamine modifies behavioral effects of morphine predicting efficacy as a novel therapy for opioid use disorder. Pharmacol. Biochem. and Behav. 194. doi: 10.1016/j.pbb.2020.172927.

Witkin, J. M., Martin, A. E., Golani, L. K., Xu, N. Z. \& Smith, J. L. 2019 Rapid-acting antidepressants. Adv. Pharmacol. 86, 47-96. doi: 10.1016/bs.apha.2019.03.002.

Witkin, J. M., Steele, T. D. \& Sharpe, L. G. 1997 Effects of strychnine-insensitive glycine receptor ligands in rats discriminating dizocilpine or phencyclidine from saline. J. Pharmacol. Exp. Ther. 280 (1), 46-52.

Yang, C., Shirayama, Y., Zhang, J. C., Ren, Q., Yao, W., Ma, M., Dong, C. \& Hashimoto, K. 2015 R-ketamine: a rapid-onset and sustained antidepressant without psychotomimetic side effects. Transl. Psychiatry 5, e632. doi: 10.1038/tp.2015.136.

Yang, Chun, Yang, Jianjun, Luo, Ailin \& Hashimoto, Kenji 2019 Molecular and cellular mechanisms underlying the antidepressant effects of ketamine enantiomers and its metabolites. Trans. Psychiatry 9 (1), 280. doi: 10.1038/s41398-019-0624-1.

Yokoyama, Reiko, Matsumoto, Satoshi, Nomura, Satoshi, Higaki, Takafumi, Yokoyama, Takeshi \& Kiyooka, Syun-ichi 2009 Enantioselective construction of nitrogen-substituted quaternary carbon centers adjacent to the carbonyl group in the cyclohexane ring: first asymmetric 
synthesis of anesthetic (S)-ketamine with high selectivity. Tetrahedron 65 (27), 5181-5191. doi: 10.1016/j.tet.2009.05.004.

Zanos, P., Highland, J. N., Liu, X., Troppoli, T. A., Georgiou, P., Lovett, J., Morris, P. J., Stewart, B. W., Thomas, C. J., Thompson, S. M., Moaddel, R. \& Gould, T. D. 2019 (R)-Ketamine exerts antidepressant actions partly via conversion to (2R,6R)-hydroxynorketamine, while causing adverse effects at sub-anaesthetic doses. Br. J. Pharmacol. 176 (14), 2573-2592. doi: 10.1111/bph.14683.

Zanos, Panos, Moaddel, Ruin, Morris, Patrick J., Riggs, Lace M., Highland, Jaclyn N., Georgiou, Polymnia, Pereira, Edna F. R., Albuquerque, Edson X., Thomas, Craig J., Zarate, Carlos A., Jr. \& Gould, Todd D. 2018 Ketamine and ketamine metabolite pharmacology: Insights into therapeutic mechanisms. Pharmacol. Rev. 70 (3), 621-660. doi: 10.1124/pr.117.015198.

Zarate, C. A., Singh, J. B., Carlson, P. J., Brutsche, N. E., Ameli, R., Luckenbaugh, D. A., Charney, D. S. \& Manji, H. K. 2006 A randomized trial of an N-methyl-D-aspartate antagonist in treatment-resistant major depression. Arch. Gen. Psychiatry 63 (8), 856-864. doi: 10.1001/archpsyc.63.8.856.

Zhang, Ji Chun, Li, Su Xia \& Hashimoto, Kenji 2014 R (-)-ketamine shows greater potency and longer lasting antidepressant effects than S (+)-ketamine. Pharmacol. Biochem. Behav. 116, 137-141. doi: 10.1016/j.pbb.2013.11.033.

Zukin, S. R., Brady, K. T., Slifer, B. L. \& Balster, R. L. 1984 Behavioral and biochemical stereoselectivity of sigma opiate/PCP receptors. Brain Res. 294 (1), 174-177. doi: 10.1016/00068993(84)91326-x. 